BMC

Evolutionary Biology

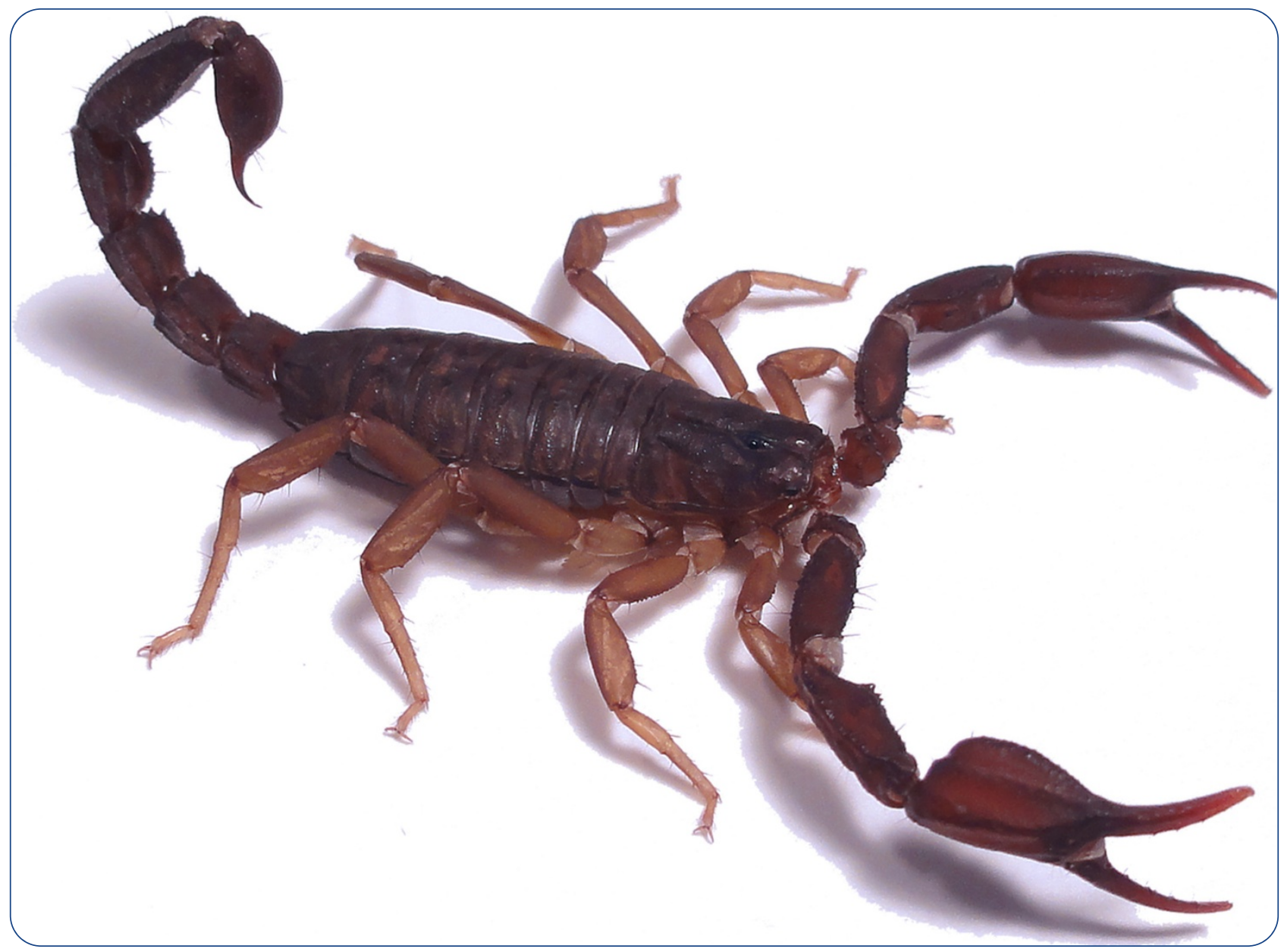

Caves as microrefugia: Pleistocene phylogeography of the troglophilic North American scorpion Pseudouroctonus reddelli

Bryson et al.

() Biomed Central 


\title{
Caves as microrefugia: Pleistocene phylogeography of the troglophilic North American scorpion Pseudouroctonus reddelli
}

\author{
Robert W Bryson $\mathrm{Jr}^{1 *}$, Lorenzo Prendini ${ }^{2}$, Warren E Savary ${ }^{3}$ and Peter B Pearman ${ }^{4}$
}

\begin{abstract}
Background: Survival in microrefugia represents an important paradigm in phylogeography for explaining rapid postglacial re-colonization by species in temperate regions. Microrefugia may allow populations to persist in areas where the climatic conditions on the surface have become unfavourable. Caves generally contain stable microclimates and may represent microrefugia for species capable of exploiting both cave and surface habitats (troglophiles). We examine the phylogeography of the troglophilic North American vaejovid scorpion Pseudouroctonus reddelli using 1,993 base pairs of mitochondrial and nuclear DNA sequence data generated from 12 populations. We use (i) descriptive measures of genetic diversity and population genetics statistics, (ii) reconstructions of phylogeographical structure, spatial diffusion during diversification, and population sizes through time, and (iii) species distribution modelling to test predictions of the hypothesis that caves serve as microrefugia. We compare phylogeographical patterns in P. reddelli with other troglophilic species across the Edwards Plateau karst region of Texas.

Results: Results revealed high haplotype and nucleotide diversity and substantial phylogeographical structure, probably generated during the Pleistocene. Spatial diffusion occurred along the southern edge of the Edwards Plateau from multiple refugia along the Balcones Escarpment. There was little evidence for population and geographical expansion. Species distribution models predicted substantial reductions in suitable epigean habitat for $P$. reddelli at the Last Glacial Maximum (LGM).

Conclusions: High genetic diversity, strong phylogeographical structure, diffusion from multiple refugia, and unfavourable climatic conditions at the LGM collectively support the hypothesis that caves served as microrefugia for P. reddelli. Similar patterns of genetic structure in P. reddelli and other troglophilic species across the Edwards Plateau karst region of Texas suggest that caves serving as microrefugia are important for the formation, maintenance, and future survival of troglophilic species in temperate karst regions.
\end{abstract}

Keywords: Last Glacial Maximum, Refugia, Species distribution model, Scorpiones, Vaejovidae

\section{Background}

The dramatic climatic oscillations of the Pleistocene profoundly impacted the geographical distribution and genetic structure of species in North America [1-3]. Parts of northern North America were periodically covered with glacial ice during the Pleistocene, resulting in dramatically fluctuating biotic communities [4]. As a result of distributional shifts, fragmentation of primary habitats,

\footnotetext{
*Correspondence: brysonjr@uw.edu

'Department of Biology and Burke Museum of Natural History and Culture, University of Washington, Box 351800, Seattle, WA 98195-1800, USA

Full list of author information is available at the end of the article
}

and the development of unfavourable climate conditions that exceeded physiological tolerances, many temperate species responded to Pleistocene climatic fluctuations with latitudinal shifts into and out of refugia [5]. Characterizing the location and extent of these climatic refugia has been the focus of phylogeographical research for decades (e.g. [1,6-8]). Climatic refugia are generally considered to be large regions in which species took refuge during glacial advances [3]. In North America such regions exist in the southeastern United States and in the Chihuahuan and Sonoran Deserts [8,9].
C Biomed Central

(c) 2014 Bryson et al.; licensee BioMed Central Ltd. This is an Open Access article distributed under the terms of the Creative Commons Attribution License (http://creativecommons.org/licenses/by/2.0), which permits unrestricted use, distribution, and reproduction in any medium, provided the original work is properly cited. The Creative Commons Public Domain Dedication waiver (http://creativecommons.org/publicdomain/zero/1.0/) applies to the data made available in this article, unless otherwise stated. 
Evidence suggests, however, that climatic refugia also occurred at local scales [10]. Microrefugia are small areas "with local favourable environmental features, in which small populations can survive outside their main distribution area, protected from the unfavourable regional environmental conditions" ([11]: pp. 482-483). The climatic conditions of microrefugia differ from those of the surrounding region in a manner conducive to the persistence of species that may not survive elsewhere $[10,12]$. The survival of species within microrefugia has broad implications for how species responses to past climate change are viewed. Rather than invoking unrealistic long-distance dispersal (e.g. [13]) or ecological niche shifts (e.g. [14]) to explain discordant genetic structure and predicted paleo-distributions, species may simply have persisted in scattered microrefugia that supported isolated, low-density populations beyond their inferred distributional boundaries during the Pleistocene [12].

An important characteristic of microrefugia is a microclimate that is both stable and sufficiently distinct from the surrounding habitat $[10,12]$. Subterranean environments such as caves provide conditions that enable species to persist during fluctuating climate [15-17]. The long-term persistence of troglobionts (obligate cave dwellers; [18]) in regions impacted by Pleistocene glaciation has been documented in several European (e.g. [19]) and North American (e.g. [20-22]) taxa. Presumably, troglophiles, uniquely able to exploit both cave and surface habitats [18], could also utilize caves as microrefugia during unfavourable climate [23]. However, the concept that caves are potential microrefugia has not been well explored, perhaps owing to the relatively few phylogeographical studies of troglophilic species in temperate regions (e.g. [24-28]).

The Texas cave scorpion, Pseudouroctonus reddelli (Gertsch \& Soleglad 1972), of the endemic North American family Vaejovidae Thorell, 1876, occurs on humid rocky hillsides and in subterranean habitats throughout the karst of the Edwards Plateau of Texas [29] (Figure 1). Although the majority of known localities are caves, $P$. reddelli exhibits no apparent ecomorphological adaptations for life in caves [30,31] and can be common on the surface in rocky areas with oak leaf litter $[29,30]$. Pseudouroctonus sprousei Francke \& Savary 2006, the sister species to $P$. reddelli [31], is troglobiotic and known from isolated caves in the arid Chihuahuan Desert in the Mexican state of Coahuila to the southwest of the Edwards Plateau.

We hypothesize that the ability of $P$. reddelli to exploit both epigean (surface) and hypogean (subterranean) habitats allowed this species to persist across their present distribution during Pleistocene climatic fluctuations. During favourable climatic conditions, the geographical distribution of $P$. reddelli across epigean habitats and genetic connectivity among populations would have been more extensive than during periods of unfavourable conditions, when epigean populations would have diminished while hypogean populations persisted in isolated microrefugia. Cyclical patterns of dispersal into and out of microrefugia during glacial-interglacial cycles, repeated throughout the Pleistocene, should produce a signature of marked genetic diversity and phylogeographical structure [12]. Genetic diversity is predicted to be retained in microrefugia during periods of unfavourable climate rather than lost, as during the extinction of recently-expanded populations with new genetic mutations [12]. Populations in scattered microrefugia represent remnants of the most recent population expansion and are predicted to be welldifferentiated [12].

In this paper, we examine the phylogeography of $P$. reddelli using mitochondrial and nuclear DNA sequence data generated from 12 populations. We calculate descriptive measures of genetic diversity and population genetics statistics, and reconstruct phylogeographical structure, spatial distribution and population sizes through time using coalescent-based methods. We create species distribution models (SDMs) to infer the climatic niche of epigean populations of $P$. reddelli and their potential distribution both presently and during the Last Glacial Maximum (LGM). We test the hypothesis that caves served as microrefugia, which predicts marked genetic diversity and phylogeographical structure, spatial diffusion from multiple refugia during diversification, and SDMs portraying dramatically reduced or displaced suitable climatic conditions at the LGM. Other combinations of low genetic diversity, signatures of recent population expansion from large refugial areas, and SDMs depicting reduced suitable habitat, or of high genetic diversity, limited phylogeographical structure, a single refugial area, and SDMs portraying no reduction or displacement of suitable climatic conditions, would support alternative hypotheses. Finally, we compare phylogeographical patterns in $P$. reddelli with other troglophilic species across the Edwards Plateau karst region of Texas.

\section{Methods}

\section{Taxon sampling and DNA sequencing}

We generated DNA sequence data from 47 samples of $P$. reddelli collected from 12 localities across its range (Figure 1, Table 1). We obtained samples from 11 surface localities and one cave locality. Pseudouroctonus reddelli lacks apparent ecomorphological modifications for life in caves and most cave localities are generally near surface localities (Figure 1). In addition, gene flow between adjacent surface and cave populations of troglophiles is often high [23]. We therefore assumed that our 


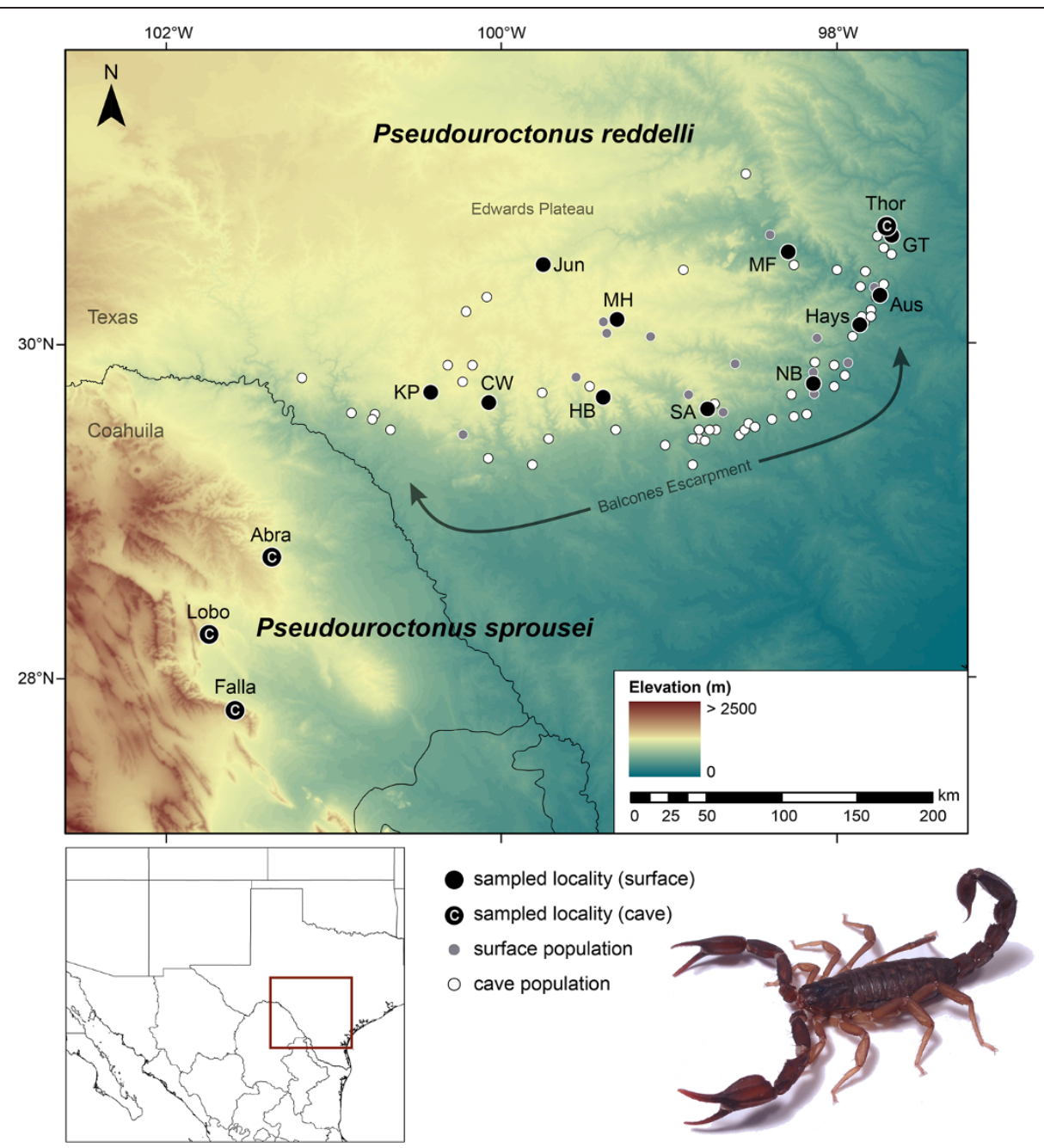

Figure 1 Known localities of the North American vaejovid scorpions Pseudouroctonus reddelli and Pseudouroctonus sprousei. Sampled localities indicated with black circles (abbreviations in Table 3). Other localities indicated with grey circles (surface populations) and white circles (cave populations), based on records from the literature $[29,30,74,75]$. The Balcones Escarpment that forms the southern edge of the Edwards Plateau in Texas is delineated.

sampling adequately captured range-wide genetic diversity. We also generated sequences from three P. sprousei samples from neighbouring Coahuila, Mexico.

We extracted genomic DNA from leg muscle tissue and generated sequences using standard protocols $[32,33]$. We sequenced two markers, including fragments of the mitochondrial (mtDNA) genes Cytochrome $c$ Oxidase subunit I (COI; 754 base pairs, bp) and $16 \mathrm{~S}$ ribosomal DNA (16S; 398 bp), and a contiguous region of nuclear DNA we collectively referred to as ITS that included partial $18 \mathrm{~S}$ rDNA (123 bp), internal transcribed spacer 1 (403 bp), 5.8S rDNA (142 bp), internal transcribed spacer 2 (209-211 bp, 156 bp used in the final alignment, see below), and partial $28 \mathrm{~S}$ rDNA (17 bp). We edited and manually aligned sequences for each individual using Sequencher v5.0 (Gene Codes Corporation, Ann Arbor, MI). We used PHASE v2.1.1 [34] to phase heterozygous sites within ITS, and retained the most probable pair of alleles for each heterozygous individual. We used three independent recombination tests (RDP, GENECOV, and MaxChi) in the program RDP v3.44 [35] to test for recombination within ITS. We applied default settings for all three methods.

\section{Genetic diversity}

We calculated descriptive measures of genetic diversity for each locus, including the number of unique haplotypes $(h)$, haplotype diversity $\left(H_{d}\right)$, and nucleotide diversity $(\pi)$, in DnaSP v5.1 [36]. We calculated several classical population genetics statistics to further test for departures from equilibrium conditions. We calculated Tajima's $D$ [37] and Fu's $F_{s}$ [38] using DnaSP. Negative and significant values reject the null hypothesis of population stasis. We calculated the sum of squares deviation 
Table 1 Locality data for genetic samples of the North American vaejovid scorpions Pseudouroctonus reddelli and Pseudouroctonus sprousei, deposited in the Ambrose Monell Cryocollection at the American Museum of Natural History, New York

\begin{tabular}{|c|c|c|c|c|c|}
\hline Sample ID & $n$ & Species & Locality & Latitude & Longitude \\
\hline Austin & 4 & P. reddelli & U.S.A.: Texas: Travis Co.: Austin & 30.2927 & -97.7491 \\
\hline Camp Wood & 4 & P. reddelli & U.S.A.: Texas: Edwards Co.: W Camp Wood & 29.6520 & -100.0749 \\
\hline Georgetown & 5 & P. reddelli & U.S.A.: Texas: Williamson Co.: Georgetown & 30.6480 & -97.6848 \\
\hline Haby Cemetery & 5 & $P$. reddelli & U.S.A.: Texas: Bandera Co.: E Haby Cemetery & 29.6832 & -99.3868 \\
\hline Hays City & 1 & $P$. reddelli & U.S.A.: Texas: Hays Co.: Hays City & 30.1246 & -97.8686 \\
\hline Junction & 4 & $P$. reddelli & U.S.A.: Texas: Kimble Co.: Junction & 30.4768 & -99.7576 \\
\hline Kickapoo & 2 & P. reddelli & U.S.A.: Texas: Edwards Co.: NE Kickapoo Caverns & 29.7166 & -100.4275 \\
\hline Marble Falls & 4 & P. reddelli & U.S.A.: Texas: Burnet Co.: SW Marble Falls & 30.5490 & -98.2920 \\
\hline Mountain Home & 5 & $P$. reddelli & U.S.A.: Texas: Kerr Co.: SE Mountain Home & 30.1487 & -99.3165 \\
\hline New Braunfels & 5 & P. reddelli & U.S.A.: Texas: Comal Co.: N New Braunfels & 29.7656 & -98.1412 \\
\hline San Antonio & 6 & P. reddelli & U.S.A.: Texas: Bexar Co.: NW San Antonio & 29.6075 & -98.7791 \\
\hline Thor's Cave & 1 & $P$. reddelli & U.S.A.: Texas: Williamson Co.: NW Georgetown & 30.6826 & -97.7077 \\
\hline Cueva Falla & 1 & P. sprousei & Mexico: Coahuila: Cueva de la Falla & 27.8134 & -101.5902 \\
\hline Cueva Lobo & 1 & P. sprousei & Mexico: Coahuila: Cueva del Lobo & 28.2667 & -101.7543 \\
\hline El Abra & 1 & P. sprousei & Mexico: Coahuila: Cueva El Abra & 28.7334 & -101.3791 \\
\hline
\end{tabular}

(SSD) and Harpending's raggedness index (RI) for the observed mismatch distributions using ARLEQUIN v3.5.1.3 [39], and compared with data simulated under a sudden expansion model. Significant $P$-values indicate rejection of the recent expansion hypothesis. We derived calculations from each complete dataset and separately for localities with sample sizes greater than or equal to four. We treated samples from Thor's Cave $(n=1)$ and Marble Falls $(n=5)$, which are $4.4 \mathrm{~km}$ apart, as a single population, and excluded Kickapoo $(n=2)$ and Hays City $(n=1)$ from the analyses.

We used a series of linear regressions to test for possible geographical gradients in genetic diversity. We calculated the Pearson's correlation coefficient $(r)$ in $\mathrm{R}$ v2.15.2 [40] to test for correlations between diversity indices $\left(H_{d}\right.$ and $\left.\pi\right)$ and latitude, longitude, and sample size for individual localities. We tested significance with 1000 permutations.

\section{Phylogeographical structure}

We estimated phylogeographical structuring and divergence dates independently for each locus using a relaxed Bayesian molecular clock framework implemented in BEAST v1.7.4 [41]. We used jModeltest v0.1.1 [42] to select the best-fit model of evolution, based on Akaike Information Criteria (AIC), for each of the two mtDNA genes. We calibrated the mtDNA tree by setting the clock-rate prior for each gene to a uniform distribution with bounds of 0.00734 and 0.00393 (COI) and 0.00486 and $0.00260(16 S)$. These values represent the number of substitutions per site per million years, derived from the inferred split of the vaejovid sister species Konetontli pattersoni (Williams 1980) and Konetontli nayarit (Armas \& Martín-Frias 2001), presumably caused by geological separation of the Cape region of the Baja California Peninsula from mainland Mexico [32]. We calculated maximum likelihood-corrected pairwise divergences between $K$. pattersoni and $K$. nayarit for $C O I$ and $16 S$ sequences (GenBank accession numbers JX909605, JX909604, JX909531, and JX909530) using MEGA v5.1 [43], and divided the resultant numbers by 14 and $7.5 \mathrm{Ma}$, the maximum and minimum ages proposed for the separation of the Cape from mainland Mexico $[44,45]$. We specified a strict clock for each gene after verification of clock-like rates using a stepping-stone model and a Bayes factor comparison in MrBayes v3.2.1 [46]. We used jModeltest to estimate the best-fit model of evolution for the ITS data. We did not partition the ITS gene region to avoid over-parameterization, given the relatively low total number of informative sites. We derived the substitution rate for ITS as above using K. pattersoni and K. nayarit and ITS2 sequences (GenBank accession numbers JX909406 and JX909405) from Bryson et al. [32]. We applied a uniform distribution with bounds of 0.00424 and 0.00187 on the clock-rate prior. We conducted analyses for 40 million generations, with samples retained every 1000 generations, using constant size coalescent tree priors for the mtDNA and the ITS loci. We displayed results in TRACER v1.5 [47] to confirm acceptable mixing and likelihood stationarity, appropriate burn-in, and adequate effective sample sizes (ESS) above 200 [48] for all estimated parameters. We 
summarized the parameter values of the samples from the posterior distribution on the maximum clade credibility tree, after discarding the first 4 million generations (10\%) as burn-in, using TreeAnnotator v1.7.4 [41].

Our divergence dates are based on estimates from a single calibration point (the inferred split of $K$. pattersoni and $K$. nayarit). We therefore conducted additional analyses with the mtDNA data using the same priors and scorpion-specific mutation rates of 0.005 substitutions/ site/million years for $16 S$ [49] and 0.007 substitutions/site/ million years for COI [50]. Although this 'scorpion clock' was calculated from buthid scorpions distantly related to $P$. reddelli, it has been used to estimate divergences within other scorpions [33,51,52], and no other mutation rates have been estimated for scorpions to date. We conducted analyses for 40 million generations and retained samples every 1000 generations.

We also assessed spatial genetic structure by testing the significance of isolation by distance (IBD) across the distribution of $P$. reddelli using the matrices of pairwise population differentiation statistics $\left(F_{S T}\right)$ and the natural logarithm of the Euclidian geographical distances. We calculated $F_{S T}$ values for genetic distances with ARLEQUIN for each locus, and generated Euclidian distances with the IBRWS web server 0.1 [53]. We subsequently used the IBD web server v3.23 [54] to check for isolation-bydistance by performing a Mantel test with 1000 random permutations.

\section{Phylogeography through time}

We inferred the geographical origin of $P$. reddelli and its spatial distribution during diversification using a relaxed random walk (RRW) diffusion model across continuous space in BEAST. This model incorporates uncertainty in the tree topology and the spatial diffusion process to reconstruct time-sliced contours from the posterior tree distribution that represent the credibility intervals for locations at any point in time [55]. We included the sister species $P$. sprousei and ran independent analyses on each locus. We edited the $\mathrm{xml}$ file, prior to analyses, to input random noise to offset identical coordinates using the jitter option with a parameter of 0.01 . We used the gamma RRW model for the continuous trait model prior. We performed analyses on the mtDNA dataset for 40 million generations using the BEAST priors specified above. We performed two independent analyses on the ITS dataset due to low ESS values (see below), each for 400 million generations with samples retained every 10,000 generations. We then combined posterior parameter estimates across the two runs using LogCombiner v1.7.4 [41]. We estimated a maximum clade credibility tree using TreeAnnotator and projected it onto the grid of geographical coordinates using SPREAD v1.0.5 [56] to visualize phylogeographical reconstructions for each locus. We visualized the $\mathrm{kml}$ file output by SPREAD in Google Earth v6.0.1 (Google Inc.).

\section{Historical demography through time}

We generated coalescent-based Gaussian Markov random field (GMRF) Bayesian skyride plots [57] with BEAST to estimate the magnitude and relative timing of changes in effective population size since the time of the most recent common ancestor. This method differs from the similar Bayesian skyline plot [58] in that the former does not require specification of strong user-defined priors for the number of population size changes during the history of the sample [57]. We performed independent analyses on the mtDNA and ITS datasets, without P. sprousei, using time-aware smoothing. Priors for the mtDNA and ITS datasets were as specified previously, but we used jModeltest to produce new best-fit models of evolution estimated for the ingroup only. We ran each dataset for 40 million generations, with samples retained every 1000 generations. We checked output files in TRACER to verify proper mixing and ESS values greater than 200 for each parameter. We subsequently reconstructed GMRF skyride plots in TRACER. Because strong population structure can violate skyride model assumptions of panmixia and potentially bias reconstructions [59], we conducted additional analyses on the two strongly supported subclades of $P$. reddelli (see below) using the mtDNA data. Regardless, we interpreted results cautiously and used them to cross-validate our descriptive statistics of departures from population size constancy (Tajima's $D$, Fu's $F_{s}$, sum of squares deviation, and Harpending's raggedness index).

\section{Species distribution modelling Climate data}

We obtained data for the climate of the study area from the WorldClim website (www.worldclim.org), at a resolution of 30 arc sec, approximately $1 \mathrm{~km}$. We chose this resolution because of the sub-continental extent of the study, the relatively restricted distribution of the species within the study area, and the availability of highresolution geographical coordinate data for species occurrence records. These climate data for North America represent an average over the period of approximately 1960-1990 [60]. We refer to this as present climate. Although estimates of local epigean climate could have provided information on climatic conditions directly experienced by $P$. reddelli, such data were unavailable for present climate or for climate modelled for the LGM. We used the results of two ocean-atmosphere coupled general circulation models (GCMs) as estimates for climate at the LGM, MIROC (A Model for Interdisciplinary Research On Climate) and CCSM (Community Climate System Model). The modelled results were produced as 
part of the PMIP2 model comparison project [61] and downscaled versions were available at 2.5 arc min resolution from the WorldClim website. We further downscaled these raster layers using an inverse distance weighting algorithm in ArcMap 10 (ESRI, Redlands, CA, USA) to interpolate the LGM climate data to 30 arc sec [62]. We represented present and LGM climate with 19 'bioclimatic' variables (see www.worldclim.org), which may bear a closer relationship with physiological limitations than simple monthly means [60].

\section{Ensemble approach and algorithms}

We chose an ensemble approach to distribution modelling in order to account for potential model-based uncertainty [63,64]. We chose four commonly used modelling algorithms. Two of these, generalized linear models (GLM) [65] and generalized additive models (GAM) [66], represented inherently statistical approaches whereas the others, boosted regression trees (BRT) [67] and maximum entropy (MaxEnt) [68,69], were machine-learning algorithms. Generalized linear models and GAMs were implemented in R, using the packages stats and gam [70,71], and BRTs and MaxEnt using the packages $g b m$ and dismo, respectively [72,73].

We used 25 occurrences of $P$. reddelli obtained from literature records $[30,74,75]$ and samples collected during the study (Table 1) for developing distribution models. Each point was a surface locality geo-referenced to within several tens of metres, and no two points occupied the same pixel of the $1 \mathrm{~km}$-resolution climate data. These occurrences constituted presence-only data and as such it was necessary to identify an encompassing area for the selection of climate background (MaxEnt) and pseudo-absence data (other algorithms). Although the role of these data differs among algorithms, we refer to them generically as pseudo-absence data. We chose an areal extent in southern North America (primarily the southern United States and Mexico) where we considered it reasonable that suitable climatic conditions for $P$. reddelli might be found presently and during the LGM. This was important because the inclusion of excessively long environmental gradients in pseudoabsence selection (e.g. by choosing the entirety of North America) may substantially over-predict the extent of distributions when modelling with presence-only data [76]. We randomly chose 2000 locations from the selected area using a function in $\mathrm{R}$ to provide pseudoabsence data. The use of several thousand randomly selected pseudo-absence points generally leads to high model performance across algorithms [77]. These data were weighted such that species prevalence in BRTs, GLMs and GAMs was effectively 0.5. Manual weighting is not possible in MaxEnt, so we selected the default prevalence value of 0.5. All cropping, downscaling and extraction of gridded climate values was done with the $\mathrm{R}$ packages raster [78], sp [79], and Rgdal [80].

\section{Overfitting, parameterization and multi-colinearity}

We constrained the models in several ways to avoid overfitting the current distribution of $P$. reddelli to the environmental data. This was important because close conformance to the training data by overfitted models (i.e. fitting error variation) may cause models to perform poorly when projected to other areas or climate datasets. The algorithm in the $g b m$ package produces models by sequentially fitting simple regression and decision trees to the occurrence and pseudo-absence data. We ensured the use of simple trees by limiting tree depth to three. We used a conservative fitting criterion ('oob') [81] and adjusted the tree weightings ('learning rate' in the $\mathrm{gbm}$ package) to reduce the chance of overfitting and ensure that the number of trees in each final BRT model was between 2000 and 8000 . We set the degrees of freedom in GAMs to three. We also set the synthetic variables generated by MaxEnt ('features') to a single type ('hinge'). We included quadratic terms for each variable in GLM models, but did not include terms expressing interactions among variables, which may also prevent obtaining models that closely fit particular correlation structures among climate variables.

The projection of SDMs to climates that differ from those used in model calibration may be complicated when climate data differ strongly in the correlation structure among the variables used in distribution models. We mitigated the tendency of algorithms to fit a particular correlation structure in climate data by limiting the number of climate variables to four when parameterizing each model. We also limited the degree of multicolinearity among the chosen variables by ensuring that the maximum variance inflation factors of the sets of four variables were less than 4.0 and the pairwise correlations of $r_{p}$ were less than 0.7. We fitted 20 models as the factorial combination of the four algorithms with five sets of uncorrelated climate variables. Each set contained two precipitation and two temperature variables (Table 2). We evaluated model performance with statistics commonly used for judging the performance of SDMs: the Area Under the Curve of the Receiver Operator Characteristic Function (AUC) [82], the proportion of presences and absences correctly categorized (pcc), the proportion of presences correctly predicted (sensitivity), and the proportion of absences correctly predicted (specificity). Each statistic was estimated for each model using 10-fold cross-validation on randomly chosen subsamples of the training data (maintaining original species prevalence) and then averaging the values.

Predictions of the current distribution of the species were formulated by determining probabilities of species 
Table 2 Climate variables from the WorldClim website (www.worldclim.org) used for parameterizing each of 20 distribution models for the North American vaejovid scorpion Pseudouroctonus reddelli

\begin{tabular}{|c|c|c|}
\hline \multirow[t]{6}{*}{ (a) } & Sets & WorldClim variables \\
\hline & 1 & Bio3, Bio8, Bio15, Bio18 \\
\hline & 2 & Bio1, Bio2, Bio8, Bio17 \\
\hline & 3 & Bio2, Bio5, Bio18, Bio19 \\
\hline & 4 & Bio5, Bio6, Bio13, Bio15 \\
\hline & 5 & Bio2, Bio8, Bio11, Bio14 \\
\hline \multirow[t]{14}{*}{ (b) } & Variable name & Variable definition \\
\hline & Bio1 & Annual mean temperature \\
\hline & $\mathrm{Bio} 2$ & Mean diurnal temperature range \\
\hline & Bio3 & Isothermality \\
\hline & Bio5 & Maximum temperature of the warmest month \\
\hline & Bio6 & Minimum temperature of the coldest month \\
\hline & Bio8 & Mean temperature of the wettest quarter \\
\hline & Bio11 & Mean temperature of the coldest quarter \\
\hline & Bio13 & Precipitation of the wettest month \\
\hline & Bio14 & Precipitation of the driest month \\
\hline & Bio15 & Precipitation seasonality \\
\hline & Bio17 & Precipitation of the driest quarter \\
\hline & Bio18 & Precipitation of the warmest quarter \\
\hline & Bio19 & Precipitation of the coldest quarter \\
\hline
\end{tabular}

(a) Variable sets used in modelling and (b) variable definitions.

presence (we used habitat suitability values for MaxEnt), conditioned on the current climate values for each $1 \mathrm{~km}$ pixel. We converted these continuous values to a Bernoulli variable that represented the presence or absence of suitable climate by tabulating model probabilities against the presence and pseudo-absence values used in model calibration. We subsequently determined the threshold probability as the value that maximized the True Skill Statistic (TSS), which previously demonstrated performance independent of species prevalence and has often been used for this purpose [83]. The use of a flexible statistic to determine the probability threshold for predicted presence has proven superior to the use of a fixed, arbitrary threshold [84]. We used the corresponding TSS value for each SDM to determine the predicted distribution of suitable climate at the LGM. We emphasized the degree of consensus among species distribution models regarding prediction of suitable climate for the species by overlaying the mapped predictions of each model to create a spatial frequency distribution.

\section{Results}

\section{Genetic data}

Parsimony-informative sites comprised $13.5 \%$ of the mtDNA dataset (COI: 111/754 bp; 16S: 45/398 bp). The nuclear ITS gene region contained less variation than the mtDNA: $10 \%$ of the sites were parsimonyinformative $(84 / 841 \mathrm{bp})$. We were unable to obtain ITS sequences from the single sample from Hays City and one sample each from Junction, Kickapoo, and Camp Wood. Nuclear data were also missing for P. sprousei from El Abra. More than half of the $P$. reddelli samples $(82 \%)$ were heterozygous for either one or two single base-pair indels within a 55-bp segment near the beginning of the ITS2 gene. Chromatograms on either side of this region (in the forward and reverse primers, respectively) were easy to read and align across all samples. We therefore discarded the intervening 55-bp section from the dataset. None of the three methods used in RDP detected recombination in the ITS dataset. We deposited sequence data in GenBank (KF982915-KF983014) and sequence alignments in the Dryad Digital Repository (http://dx.doi.org/10.5061/dryad.66rd8).

\section{Genetic diversity}

Thirty-two unique mtDNA haplotypes were found among the 47 samples of $P$. reddelli sequenced, none of which were shared among localities. Thirty-two of the 86 phased ITS alleles were unique and twelve were not shared among localities (Austin, 4; San Antonio, 3; New Braunfels, 2; and Junction, Mountain Home, and Camp Wood, 1 each). Mean haplotype and nucleotide diversity estimates were relatively high: $0.9800\left(H_{d}\right)$ and $0.0156(\pi)$ for all mtDNA samples combined; $0.8860\left(H_{d}\right)$ and $0.0042(\pi)$ for ITS. The $H_{d}$ and $\pi$ estimates for sample localities indicated the lowest genetic diversity values were observed in the Marble Falls and Junction populations (Table 3). There were no significant correlations between diversity indices and longitude or between diversity indices and sample size (Additional file 1). Similarly, no significant correlations were found between $\pi$ and latitude. However, there were significant correlations between $H_{d}$ and latitude in both loci (mtDNA: $r=-0.6718, P=0.0475$; ITS: $r=-0.7603, P=0.0174$ ).

Descriptive statistics of departure from population size constancy were ambiguous, but no combinations of the four independent estimates strongly supported population expansion. Tajima's $D$ and Fu's $F s$ values could not reject the null hypothesis of population stasis with one exception (Table 3 ). In this case, Fu's $F_{s}$ statistic was significantly negative for the ITS data combined $\left(F_{s}=-20.6848, P<0.01\right)$. The SSD and RI calculated for the observed mismatch distributions (Table 3) failed to reject the null hypothesis of recent population expansion for three populations based on mtDNA (SSD: Austin, New Braunfels; RI: San Antonio) and for the complete mtDNA dataset (RI).

\section{Phylogeographical structure}

The GTR + I + G (CO1) and HKY + I + G (16S and ITS) models of sequence evolution were selected using 
Table 3 Measures of genetic diversity for the North American vaejovid scorpion Pseudouroctonus reddelli, including sample size $(n)$, number of unique haplotypes $(h)$, haplotype diversity $\left(H_{d}\right)$, nucleotide diversity $(\pi)$, Tajima's $D$, Fu's $F_{s}$, sum of squares deviation (SSD), and Harpending's raggedness index (RI)

\begin{tabular}{|c|c|c|c|c|c|c|c|c|c|c|c|c|c|c|c|c|}
\hline \multirow[b]{2}{*}{ Locality } & \multicolumn{8}{|c|}{ mtDNA } & \multicolumn{8}{|c|}{ ITS } \\
\hline & $n$ & $h$ & $H_{d}$ & $\pi$ & $D$ & $F_{s}$ & SSD & RI & $n$ & $h$ & $H_{d}$ & $\pi$ & $D$ & $F_{s}$ & SSD & RI \\
\hline$\overline{\mathrm{GT}}$ & 6 & 3 & 0.6000 & 0.0051 & -1.3152 & 3.3578 & 0.2035 & 0.4533 & 12 & 5 & 0.7880 & 0.0032 & 2.2171 & 0.4605 & 0.0336 & 0.0826 \\
\hline Aus & 5 & 4 & 0.9000 & 0.0093 & -0.2287 & 1.7144 & 0.2151 & 0.5900 & 10 & 6 & 0.8440 & 0.0047 & -0.2812 & -0.1484 & 0.0468 & 0.1269 \\
\hline MF & 4 & 2 & 0.5000 & 0.0004 & -0.6124 & 0.1719 & 0.0219 & 0.2500 & 8 & 3 & 0.7140 & 0.0012 & 1.1039 & 0.2043 & 0.0087 & 0.1225 \\
\hline NB & 5 & 4 & 0.9000 & 0.0056 & 0.8036 & 0.8832 & 0.2112 & 0.5900 & 10 & 7 & 0.9330 & 0.0050 & -0.0445 & -1.1634 & 0.0491 & 0.1437 \\
\hline SA & 6 & 4 & 0.8670 & 0.0064 & 0.2878 & 1.9308 & 0.1831 & 0.4889 & 12 & 8 & 0.9390 & 0.0039 & 0.4190 & -2.2709 & 0.0611 & 0.1607 \\
\hline $\mathrm{HC}$ & 5 & 5 & 1.0000 & 0.0043 & -0.9543 & -1.3451 & 0.0609 & 0.1200 & 10 & 4 & 0.8220 & 0.0034 & 1.4113 & 1.4153 & 0.0088 & 0.0385 \\
\hline $\mathrm{MH}$ & 5 & & 0.8000 & 0.0097 & -0.4962 & 4.0693 & 0.2350 & 0.5200 & 10 & 4 & 0.7330 & 0.0024 & 0.5276 & 0.5924 & 0.0711 & 0.2064 \\
\hline Jun & 4 & 1 & 0.0000 & 0.0000 & 0.0000 & 0.0000 & 0.0000 & 0.0000 & 6 & 3 & 0.7330 & 0.0047 & 1.6471 & 2.3987 & 0.1648 & 0.2756 \\
\hline$C W$ & 4 & 3 & 0.8330 & 0.0035 & 0.4671 & 1.1632 & 0.2223 & 0.7500 & 6 & 4 & 0.8670 & 0.0020 & 1.3861 & -0.8336 & 0.0758 & 0.2933 \\
\hline All & 47 & 32 & 0.9800 & 0.0156 & -0.4569 & -3.5808 & 0.0032 & 0.0109 & 86 & 32 & 0.8860 & 0.0042 & -0.8142 & -20.6848 & 0.0038 & 0.0120 \\
\hline
\end{tabular}

Values of $F_{s}$ and Tajima's $D$ in boldface indicate rejection of the hypothesis of constant population size $(P<0.05)$. SSD and RI values in boldface indicate failure to reject the hypothesis of recent expansion $(P>0.05)$. Sampled localities are abbreviated as follows: Georgetown (GT), Austin (Aus), Marble Falls (MF), New Braunfels (NB), San Antonio (SA), Haby Cemetery (HC), Mountain Home (MH), Junction (Jun), and Camp Wood (CW). Sample size for the nuclear internal transcribed spacer region (ITS) represents the number of phased alleles.

jModeltest. Initial analyses of the mtDNA dataset revealed low ESS values $(<100)$ for several parameters associated with the GTR model. We therefore used the less complex HKY model in final analyses, which resulted in higher (> 200) ESS values. The mtDNA gene tree (Figure 2a) indicated strong phylogeographical structure across the distribution of $P$. reddelli. Samples from most populations grouped together; only samples from Austin and Mountain Home were not monophyletic. Relationships among populations were generally unsupported throughout the tree. However, two strongly supported subclades were evident. One subclade contained the Junction, Marble Falls, Kickapoo, and Camp Wood samples along with one sample from Mountain Home. The second subclade was comprised of the Georgetown samples, the sample from nearby Thor's Cave, and three samples from Austin.

Divergence dates estimated using the vaejovid calibration and the buthid 'scorpion clock' calibration differed (Table 4). Divergences inferred using the vaejovid calibration were older, and this was especially evident at the base of the tree. However, differences between mean estimated divergence dates within $P$. reddelli were relatively minor, ranging from $0.5 \mathrm{Ma}$ (at the most recent common ancestor of $P$. reddelli) to $0.03 \mathrm{Ma}$ (at the most recent common ancestor of the Marble Falls population), and all were within the Pleistocene (Table 4). We consider results based on the vaejovid calibration to be our best estimate of divergence dates because the species used to derive the calibration were vaejovid scorpions more closely related to $P$. reddelli and $P$. sprousei, but we acknowledge the drawbacks of basing conclusions on a single calibration derived from taxa outside of the focal group [85].
Divergence time estimates using our preferred vaejovid calibration contained wide 95\% highest posterior density (HPD) intervals, especially at the base of the tree. The split between $P$. sprousei and $P$. reddelli occurred tens of millions of years before the Pleistocene (mean $=49.3$ Ma; 95\% HPD = 28.9-73.2 Ma). Early diversification within $P$. reddelli probably began near the Pliocene-Pleistocene boundary around 2.6 Ma. Subsequent divergences within $P$. reddelli based on mean estimates all occurred within the Pleistocene, but predated the LGM at around 0.02 Ma.

Strong phylogeographical structure within $P$. reddelli was also evident based on ITS data (Figure 3a). However, only one population (Marble Falls) was exclusively monophyletic and few nodes received greater than 0.95 posterior probability support. Mean estimates of divergence times were younger and 95\% HPDs were wider than those based on the mtDNA data, but supported a relatively ancient divergence between $P$. sprousei and $P$. reddelli, a probable origin of $P$. reddelli near the beginning of the Pleistocene, and range-wide diversification within $P$. reddelli entirely within the Pleistocene, based on mean estimated divergence dates. Further, mean estimated divergences for all but one node predated the LGM. The limited resolution obtained is consistent with the relatively few phylogenetically informative characters and the large number of heterozygous positions within the ITS region (177 across 24 polymorphic sites). Visualization of the data in a network (Additional file 2) revealed no novel insights compared to the Bayesian tree-based approach. The Mantel test revealed no significant correlation between geographical and genetic distances in the mtDNA $(r=0.12$, one-sided $P=0.26)$ and ITS $(r=-0.29$, one-sided 
(a)

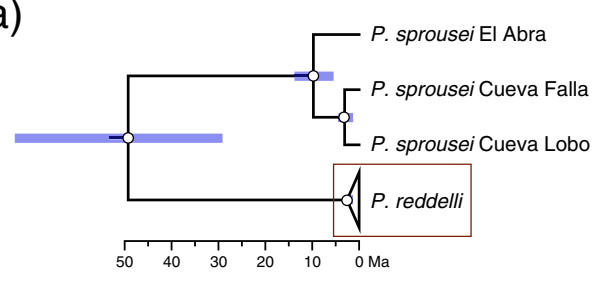

(b)

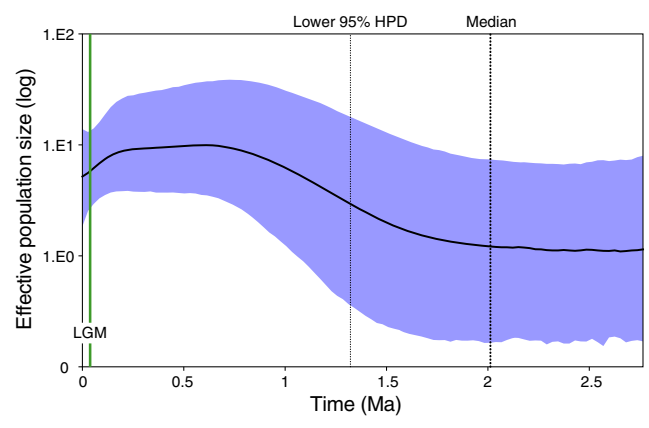

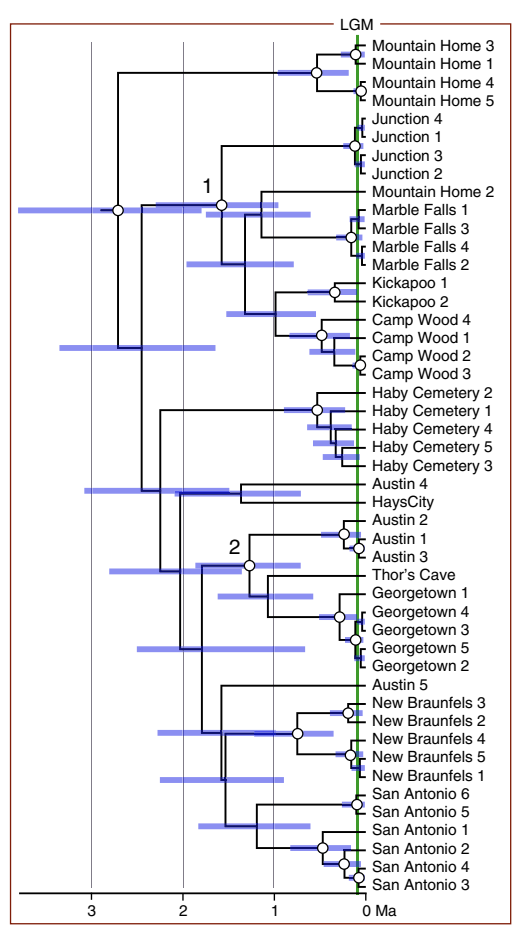

Figure 2 Phylogeographical structure and demographic reconstruction through time inferred from 1,152 base pairs of mitochondrial DNA for the North American vaejovid scorpions Pseudouroctonus reddelli and Pseudouroctonus sprousei. (a) Time-calibrated Bayesian gene tree for $P$. reddelli and $P$. sprousei. Nodes that received $\geq 0.95$ posterior probability support depicted with white dots. Two strongly supported subclades of $P$. reddelli are numbered (1 and 2). (b) Bayesian skyride plot for $P$. reddelli, showing change in effective population size of females since the time of the most recent common ancestor. HPD = highest posterior density; LGM = Last Glacial Maximum.

$P=0.97)$ datasets. These results suggest that phylogeographical structure was probably not caused by differences in interpopulation gene flow across the range of $P$. reddelli.

\section{Phylogeography through time}

Preliminary BEAST analyses using the RRW model and the ITS data for 40 million generations, sampling every 1000 generations, resulted in low ESS values and poor convergence between analyses for three parameters associated with the RRW model (traitLikelihood, col1, and col2). We obtained higher ESS values ( $>150)$ by performing analyses from different starting seeds for 400 million generations and sampling every 10,000 generations. We then combined posterior parameter estimates from two of these analyses that demonstrated convergence for all parameters using LogAnnotator. Visualization of the results from all independent analyses and the final combined analysis in GoogleEarth indicated similar phylogeographical patterns, differing only slightly in the extent of spatial uncertainty. The spatial distribution of $P$. reddelli from the final combined analysis corresponded reasonably well with spatial patterns from the mtDNA (Figure 4), further supporting the robustness of the data.
The spatial diffusion of $P$. reddelli through time, reconstructed from the mtDNA and ITS data (Figure 4) were in general similar, and differed mainly in the timing and extent of the ancestral origin of $P$. reddelli. Differences in timing were consistent with younger dates inferred from the ITS data in BEAST analyses. The mtDNA data suggested that $P$. reddelli originated near the centrally located Mountain Home and Haby Cemetery localities during the Early Pleistocene, about 2.5

Table 4 Estimated divergence dates based on two different calibration methods using 1,152 base pairs of mitochondrial DNA for the North American vaejovid scorpions Pseudouroctonus reddelli and Pseudouroctonus sprousei

\begin{tabular}{lll}
\hline Node & $\begin{array}{l}\text { Baja vaejovid } \\
\text { calibration }\end{array}$ & $\begin{array}{l}\text { buthid 'scorpion } \\
\text { clock' }\end{array}$ \\
\hline P. sprousei/P. reddelli & $49.25(28.94-73.24)$ & $39.16(24.85-54.95)$ \\
P. reddelli & $2.58(1.70-3.61)$ & $2.08(1.51-2.67)$ \\
Subclade 1 & $1.45(0.86-2.13)$ & $1.17(0.76-1.62)$ \\
Subclade 2 & $1.40(0.78-2.07)$ & $1.13(0.69-1.57)$ \\
New Braunfels & $0.81(0.37-1.31)$ & $0.64(0.31-0.99)$ \\
Marble Falls & $0.16(0.02-0.34)$ & $0.13(0.02-0.27)$ \\
\hline
\end{tabular}

Referenced nodes are indicated in Figure 2. Divergence times in millions of years are followed by $95 \%$ posterior density intervals in parentheses. 


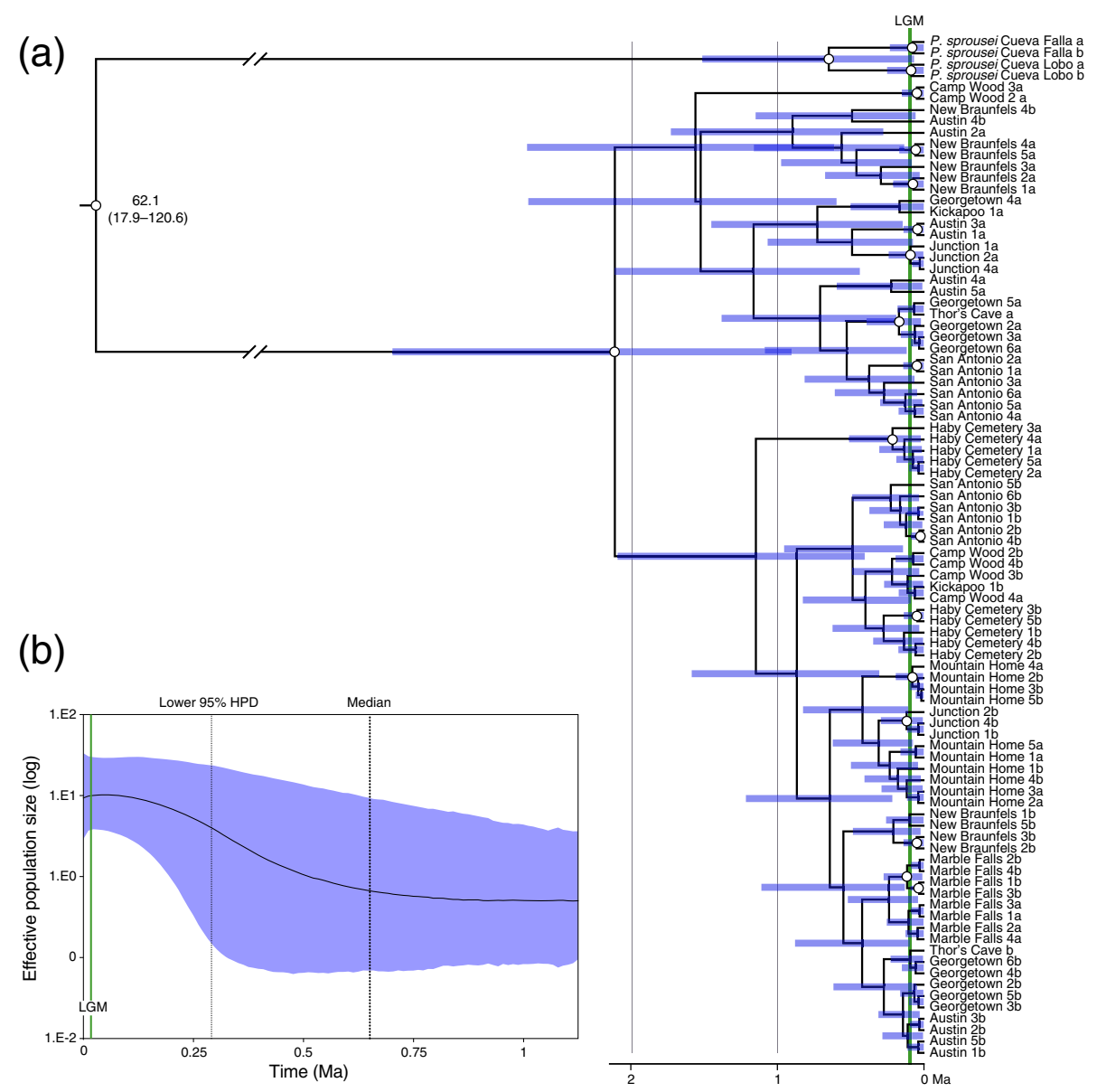

Figure 3 Phylogeographical structure and demographic reconstruction through time inferred from 841 base pairs of the nuclear internal transcribed spacer region (ITS) for the North American vaejovid scorpions Pseudouroctonus reddelli and Pseudouroctonus sprousei. (a) Time-calibrated Bayesian gene tree for P. reddelli and P. sprousei. Nodes that received $\geq 0.95$ posterior probability support depicted with white dots. (b) Bayesian skyride plot for $P$. reddelli, showing change in effective population size since the time of the most recent common ancestor. HPD = highest posterior density; LGM = Last Glacial Maximum.

Ma. Subsequent diffusion occurred along the southern edge of the Edwards Plateau from multiple refugia along the Balcones Escarpment. Final dispersal events to the northern Marble Falls and Junction localities occurred during the Late Pleistocene, around 0.1 Ma. Based on the ITS data, $P$. reddelli originated along the southern edge of the Edwards Plateau around 1.5 Ma. As with reconstructions based on the mtDNA data, final dispersal events occurred to the Marble Falls and Junction localities. Missing ITS data for the divergent sample of $P$. sprousei from El Abra may explain why $P$. sprousei appeared to originate late in the Pleistocene, rather than millions of years earlier as suggested by the mtDNA data.

\section{Historical demography through time}

The GTR + I (CO1), HKY + G (16S), and HKY + I (ITS) models of sequence evolution were selected for the ingroup using jModeltest. However, as with the BEAST analyses discussed above, we changed the GTR model to the less complex HKY model for the COI partition to obtain adequate ESS values. Bayesian skyride plots reconstructed from the mtDNA (Figure 2b) and ITS (Figure 3b) data yielded similar results. The overall pattern was similar but, as with previous analyses, the estimated time was different; divergence date estimates based on ITS were younger than those based on mtDNA. Bayesian skyride plots for both loci suggested a relatively stable population size after origination, a gradual increase in population size (2-1 Ma during the Early Pleistocene, based on mtDNA, and 0.3-0.1 Ma during the Middle Pleistocene, based on ITS), and a return to relative population stasis (from the Late Pleistocene through the present). The mtDNA suggested a possible decrease in population size towards the end of the Pleistocene, but this may be an artefact of violating the model assumption of population admixture. This interpretation is further supported by the Bayesian skyride plots for the two mtDNA subclades (Additional file 3), 
Figure 4 Reconstructions of the spatial history of the North American vaejovid scorpions Pseudouroctonus reddelli and Pseudouroctonus sprousei based on Bayesian analyses of mitochondrial DNA (solid line) and nuclear internal transcribed spacer region (ITS) data (dashed line). Polygons represent $80 \%$

highest posterior density intervals for the spatial location of ancestral populations across four time slices. Abbreviations for sampled localities in Table 3.

both of which suggested relatively stable populations during this time. Bayesian skyride plots did not provide strong evidence for a dramatic population expansion, consistent with results of our other demographic analyses.
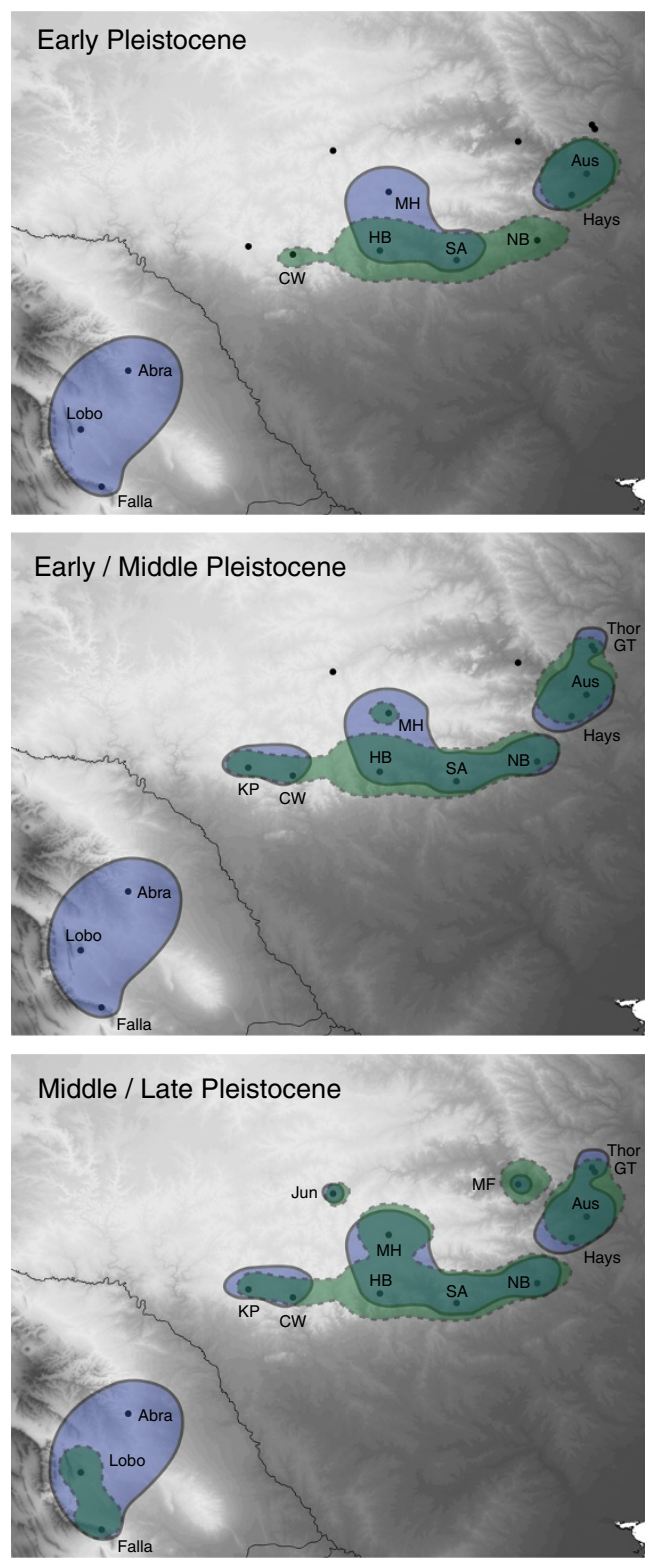

\section{Species distribution modelling}

The performance of the 20 models was high in 10-fold cross-validation of AUC $(0.959 \pm 0.010$, mean $\pm \mathrm{sd})$. Determination of the threshold probability for predicted presence using TSS resulted in a mean proportion of correctly classified training observations of $0.925 \pm 0.016$. We observed that the sensitivity of models was in all cases maximal $(1.0 \pm 0.0)$, and values of specificity were also high $(0.924 \pm 0.016)$. A strong consensus of 17 to 20 models predicted a current distribution of suitable climate for $P$. reddelli that clustered tightly around the known locations used in model training (Figure 5a).

Consensus predictions of the distribution of suitable climate for $P$. reddelli during the LGM differed substantially from predictions of the distribution of presently suitable climate. Only 5 to 8 of the 20 models projected upon the LGM climate estimate produced by the CCSM GCM predicted the presence of suitable conditions across the present distribution of $P$. reddelli (Figure $5 b$ ). None of the 20 models projected upon the LGM climate estimate of the MIROC GCM predicted the existence of suitable climate across the present distribution of the species. Instead, 5 to 8 models predicted the existence of suitable conditions during the LGM approximately $400 \mathrm{~km}$ to the south of the present distribution (Figure 5c). The majority of models did not support the presence of suitable climate during the LGM in any part of the study area under either climate estimate.

\section{Discussion}

\section{Phylogeography of $P$. reddelli}

Results suggest a history of Pleistocene diversification within $P$. reddelli and support the hypothesis that caves served as microrefugia for this species. Multiple lines of genetic evidence support a general model of distributional stasis in $P$. reddelli over an alternative hypothesis of geographical expansion. Haplotype and nucleotide diversity are high (Table 3 ), substantial phylogeographical structure is evident (Figures 2 and 3), and 


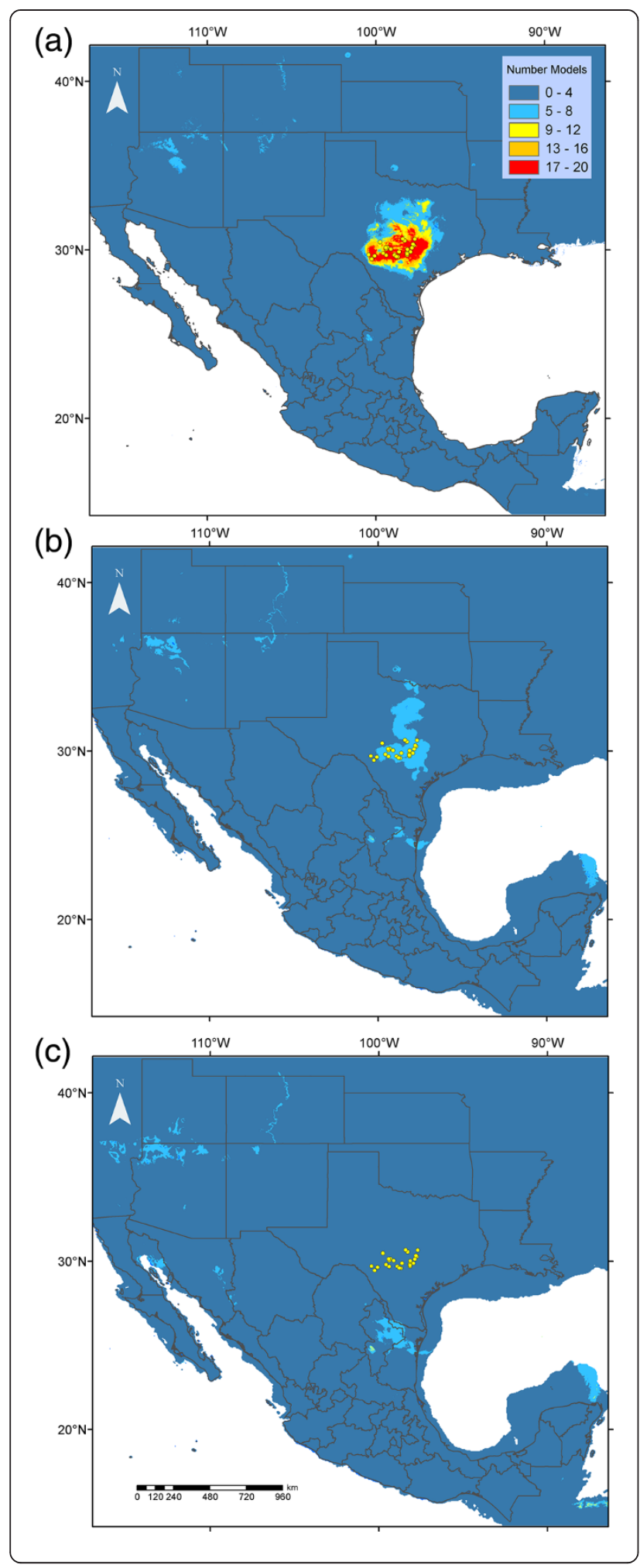

Figure 5 Predicted distribution of suitable climate for the North American vaejovid scorpion Pseudouroctonus reddelli, produced by an ensemble of 20 species distribution models. Models were the product of the factorial combination of four modelling algorithms with five sets of uncorrelated variables. Dots indicate the locations of 25 surface occurrences for $P$. reddelli used to develop distribution models. Colours indicate the number of models that predict the presence of suitable climate at present, as represented in gridded layers from WorldClim (a), and during the Last Glacial Maximum, as represented by the CCSM (b) and MIROC (c) general circulation models.

the results broadly suggest population and geographical expansion was minimal (Table 3, Figures 2b, 3b, 4). High haplotype diversity in conjunction with high nucleotide diversity usually indicates a historically stable population $[1,5]$ and is a genetic signature predicted by the microrefugia model [12]. Conversely, an ensemble of SDMs suggests that suitable epigean habitat for $P$. reddelli during the Pleistocene significantly decreased by the LGM and may have shifted several hundred kilometres to the south (Figure 5). The ability of $P$. reddelli to inhabit both surface and subterranean habitats probably allowed this scorpion to persist in caves scattered across its current distribution during cycles of unfavourable Pleistocene climate. Cave populations have likely retained genetic diversity, which has accumulated through time rather than been lost during changes in distribution. Such a scenario would explain the seemingly contradictory results from the genetic data and distribution models.

Pseudouroctonus reddelli probably diverged from its sister species, $P$. sprousei, during the Miocene and subsequently colonized the Edwards Plateau region in the early Pleistocene (Figures 2, 3 and 4). Similar deep divergences in the Miocene have been inferred for other North American vaejovid scorpions [32,33,52]. This colonization may have followed the MiocenePliocene formation of the Balcones fault zone and erosion of the Edwards Plateau into a karst region [86-88]. Results from the RRW diffusion models suggest populations then expanded out from multiple refugia along the cave-rich area of the Balcones Escarpment and reached current distributional limits by the late Pleistocene (Figure 4). Given the dramatic reduction in predicted suitable habitat at the LGM during the late Pleistocene (Figure 5), dispersal of $P$. reddelli from cave microrefugia may have occurred during warmer interglacial periods, but was arrested during cooler glacial periods, which accounted for about $80 \%$ of the Pleistocene [89]. Prolonged duration in cave microrefugia may also explain why most sampled localities showed no evidence of admixture and formed monophyletic groups based on the faster-sorting mtDNA (Figure 2). The last inferred dispersals were to the northern Marble Falls and Junction localities late in the diversification history of $P$. reddelli. 
This slight northward expansion would explain the significant correlation between haplotype diversity $\left(H_{d}\right)$ and latitude and the low genetic diversity values within the populations at both localities.

The observed high genetic diversity, strong phylogeographical structure, spatial diffusion from multiple refugia, and unfavourable climatic conditions at the LGM collectively support the hypothesis that caves served as microrefugia for $P$. reddelli. However, there may be alternative explanations for the pattern observed. Scorpions are generally poor dispersers which increases their propensity to show strong phylogeographical structure [18]. Although several recent studies of North American scorpions suggest that Pleistocene glacial-interglacial periods may have had relatively little impact on distributions and genetic structure [32,33], other studies have found strong evidence for recent postglacial range expansions and relatively weak phylogeographical structure [51,90-92]. These findings suggest that Pleistocene climate change had a potentially strong impact on the diversification of some North American scorpion species and that not all species exhibit strong phylogeographical structure. It is possible that $P$. reddelli persisted in scattered surface localities across the Edwards Plateau during Pleistocene glacial-interglacial periods, thus making caves insignificant for the survival of this species. A small minority of the total number of SDM models in fact predict fragmented patches of suitable habitat across the Edwards Plateau at the LGM (Figure 5). However, not every single model is expected to show the same pattern; this is the point of using an ensemble modelling approach. Climatic variation during stadial-interstadial cycling may also have affected the distribution of suitable climate, but no suitable climate models are available to examine this possibility. The evidence is strongly against the presence of suitable surface conditions during the LGM.

\section{Caves as microrefugia}

The locations of microrefugia have important implications for phylogeographical research as they may influence perceptions about the genetic diversity and spatial distribution of species in response to climate change. Several abiotic factors impact the formation of microrefugia including slope, exposure, and elevation [10]. As a result, microrefugia in temperate regions often occur in regions of topographical complexity $[10,12,93]$. However, even relatively tiny areas with stable environments, such as aquatic springs, can serve as microrefugia [12]. Karst landscapes are pocketed with caves containing stable environments. Across temperate regions of the world, caves probably served as microrefugia for troglophilic species during the Pleistocene, as evidenced by the distribution of $P$. reddelli across the Edwards Plateau.
During favourable environmental conditions, gene flow would have increased across the epigean habitats of troglophilic species [23]. As environmental conditions deteriorated and epigean populations diminished, cave populations would have persisted in isolated microrefugia. A cyclical pattern of dispersal into and out of cave microrefugia, in response to Pleistocene glacial-interglacial cycles, should produce marked genetic diversity and phylogeographical structure in troglophilic species. In addition, species distribution models should predict a dramatic reduction or shift in suitable habitat concurrent with climate oscillations associated with glacialinterglacial cycles. These expectations (high genetic diversity, strong phylogeographical structure, diffusion from multiple refugia, and significantly reduced or shifted Pleistocene surface habitats) should form the basis for future tests of the hypothesis that caves served as microrefugia for troglophilic species in temperate regions. Evidence from multiple co-distributed troglophilic species would further strengthen this hypothesis and help to discriminate among common patterns and idiosyncratic (e.g., species-specific) patterns, which might be the case with $P$. reddelli.

\section{Phylogeography of Edwards Plateau karst species}

Our study adds to a small number of phylogeographical studies on Edwards Plateau karst species. Much of this research has focused on terrestrial and aquatic salamanders [94-97], some of which are cave-obligate (troglobiotic) species. The phylogeography of invertebrates such as troglophilic cave crickets [98] and troglomorphic cave spiders [88,99] has also been studied. These studies revealed a pervasive pattern of relatively high genetic divergence and considerable phylogeographical structuring within or among species. The depth of phylogeographical structure includes relatively deep divergences (cave spiders: most pairwise divergences between taxa $>5 \%$ ), moderate divergences (terrestrial and aquatic salamanders: most pairwise divergences around 3-5\%), and relatively shallow divergences (cave crickets: most pairwise divergences $<3 \%$ ). Pseudouroctonus reddelli appears to be at the lower end of this range with average mtDNA pairwise divergences between localities ranging from 2.4\% (New Braunfels/Junction) to $1 \%$ (Camp Wood/Kickapoo). Taylor et al. [98] noted genetic discontinuities near the Colorado River in several karst species, including cave crickets, troglobiotic harvestmen, aquatic isopods, and terrestrial and aquatic salamanders. Most $P$. reddelli from north of the Colorado River (Austin, Georgetown, and Thor's Cave localities) also form a distinct group in the mtDNA tree (subclade 2 in Figure 2), indicating that the Colorado River is probably a barrier to dispersal for many karst species, as previously suggested [98]. 


\section{Implications for cave conservation}

Cave systems often harbour endemic troglobiotic species and frequently receive special legal protection. However, caves in temperate regions should be further prioritized for conservation because many serve as microrefugia for troglophilic species. Caves provide relatively stable microclimates during times of climate change and can facilitate persistence of troglophilic species even as their regional epigean populations diminish. As favourable environmental conditions reappear, expansion from cave microrefugia may allow some populations to respond rapidly to climate change [12]. Accordingly caves can potentially ameliorate the negative effects of anthropogenic barriers to dispersal. Caves serving as microrefugia appear to have been important in the formation and maintenance of epigean populations in temperate karst regions and are likely to continue to be important for their future survival in response to climate change.

\section{Conclusions}

Our findings support the hypothesis that caves served as microrefugia for $P$. reddelli. The ability of this scorpion to exploit both epigean and hypogean habitats probably allowed it to persist across its present distribution during Pleistocene climatic fluctuations. Similar patterns of genetic structure in $P$. reddelli and other troglophilic species across the Edwards Plateau karst region of Texas suggest that caves serving as microrefugia are important for the formation, maintenance, and future survival of troglophilic species in temperate karst regions.

\section{Availability of supporting data}

Sequence data used in this study have been deposited in GenBank (KF982915-KF983014) and the Dryad Digital Repository (http://dx.doi.org/10.5061/dryad.66rd8).

\section{Additional files}

Additional file 1: Correlations, based on Pearson's correlation coefficient $(r)$, between diversity indices (haplotype diversity, $H_{d}$, and nucleotide diversity, $\pi$ ) calculated from mitochondrial DNA (mtDNA) and nuclear internal transcribed spacer region (ITS) DNA sequence data, and latitude, longitude, and sample size for localities of the North American vaejovid scorpion Pseudouroctonus reddelli. Significant correlations $(P<0.5)$ indicated in boldface.

Additional file 2: Network of phased internal transcribed spacer region (ITS) alleles from 43 samples of the North American vaejovid scorpion Pseudouroctonus reddelli.

Additional file 3: Bayesian skyride plots inferred from 1,152 base pairs of mitochondrial DNA showing change in effective population size of females in two strongly supported subclades of the North American vaejovid scorpion Pseudouroctonus reddelli since the time of the most recent common ancestor. HPD = highest posterior density; LGM = Last Glacial Maximum.

\section{Competing interests}

The authors declare that they have no competing interests.

\section{Authors' contributions}

RWB, LP, WES, and PBP designed the research; RWB and LP acquired the samples; RWB and LP obtained the genetic data; RWB and PBP analysed the data; RWB wrote the manuscript with contributions from all authors, who read and approved the final manuscript.

\section{Acknowledgments}

We thank HM Burrell, L Colucci, A Gluesenkamp, OF Francke, TD Hibbitts, R Howe, J Huff, J Krejca, B McMinn, KJ McWest, R Moyer, R Myers, M Sanders, C Savvas, and $\mathrm{P}$ Sprouse for assisting with fieldwork and/or providing samples for analysis; and O Delgado, M Mosier and P Rubi for generating DNA sequence data at the AMNH. Fieldwork in Mexico was conducted under permits granted by SEMARNAT to OF Francke. Other support and assistance was provided by CA Brown, O Delgado, E González, J Grummer, J Huff, J Klicka, KJ McWest, and R Mercurio. Aspects of the work conducted at the AMNH were funded by National Science Foundation grants DEB 0413453 and DEB 0228699, and by a grant from the Richard Lounsbery Foundation to L Prendini.

\section{Author details}

${ }^{1}$ Department of Biology and Burke Museum of Natural History and Culture, University of Washington, Box 351800, Seattle, WA 98195-1800, USA.

2Division of Invertebrate Zoology, American Museum of Natural History, Central Park West at 79th Street, New York, NY 10024-5192, USA.

${ }^{3}$ Department of Entomology, California Academy of Sciences, 55 Music Concourse Drive, Golden Gate Park, San Francisco, CA 94118, USA.

${ }^{4}$ Landscape Dynamics Unit, Swiss Federal Research Institute WSL,

Zuercherstrasse 111, Birmensdorf CH-8903, Switzerland.

Received: 9 November 2013 Accepted: 2 January 2014

Published: 16 January 2014

\section{References}

1. Hewitt GM: Some genetic consequences of ice ages, and their role in divergence and speciation. Biol J Linn Soc 1996, 58:247-276.

2. Avise JC: Phylogeography: The History and Formation of Species. Cambridge, Massachusetts: Harvard University Press; 2000.

3. Hewitt GM: The genetic legacy of the quaternary ice ages. Nature 2000, 405:907-913.

4. Webb T III, Bartlein PJ: Global changes during the last 3 million years: climatic controls and biotic responses. Ann Rev Ecol Syst 1992, 23:141-173.

5. Hewitt GM: The structure of biodiversity - insights from molecular phylogeography. Front Zool 2004, 1:4.

6. Hoffmann RS: Different voles for different holes: environmental restrictions on refugial survival of mammals. In Evolution today. Proceedings of the Second International Congress of Systematics and Evolutionary Biology. Edited by Scudder GGE, Reveal JL. Pittsburgh, Pennsylvania: Carnegie-Mellon University; 1981:25-45.

7. Avise JC, Walker D: Pleistocene phylogeographic effects on avian populations and the speciation process. Proc $R$ Soc B 1998, 265:457-463.

8. Waltari E, Hijmans RJ, Peterson AT, Nyari AS, Perkins SL, Guralnick RP. Locating Pleistocene refugia: comparing phylogeographic and ecological niche model predictions. PLOS ONE 2007, 2:e563.

9. Swenson NG, Howard DJ: Clustering of contact zones, hybrid zones, and phylogeographic breaks in North America. Am Nat 2005, 166:581-591.

10. Dobrowski SZ: A climatic basis for microrefugia: the influence of terrain on climate. Glob Change Biol 2011, 17:1022-1035.

11. Rull V: Microrefugia. J Biogeogr 2009, 36:481-484.

12. Mosblech NA, Bush MB, Van Woesik R: On metapopulations and microrefugia: palaeoecological insights. J Biogeogr 2011, 38:419-429.

13. Clark JS, Fastie C, Hurtt G, Jackson ST, Johnson C, King GA, Lewis M, Lynch J, Pacala S, Prentice C, Schupp EW, Webb T, Wyckoff P: Reid's paradox of rapid plant migration. Bioscience 1998, 48:13-24.

14. Jezkova T, Olah-Hemmings $V$, Riddle BR: Niche shifting in response to warming climate after the last glacial maximum: inference from genetic data and niche assessments in the chisel-toothed kangaroo rat (Dipodomys microps). Glob Change Biol 2011, 17:3486-3502.

15. Howarth FG: Ecology of cave arthropods. Ann Rev of Entomology 1983, 28:365-389. 
16. Juberthie C: The diversity of the Karstic and pseudokarstic hypogean habitats in the world. In Subterranean Ecosystems. Edited by Wilkens $\mathrm{H}$, Culver DC, Humphreys WF. Amsterdam: Elsevier; 2000:17-39.

17. Prendini L, Francke OF, Vignoli V: Troglomorphism, trichobothriotaxy and typhlochactid phylogeny (Scorpiones, Chactoidea): more evidence that troglobitism is not an evolutionary dead-end. Cladistics 2010, 26:117-142

18. Prendini L: Substratum specialization and speciation in Southern African scorpions: the effect hypothesis revisited. In Memoriam Gary A. Polis. Edited by Fet V, Selden PA. Bucks, UK: British Arachnological Society, Burnham Beeches; 2001:113-138.

19. Allegrucci G, Todisco V, Sbordoni V: Molecular phylogeography of Dolichopoda cave crickets (Orthoptera, Rhaphidophoridae): a scenario suggested by mitochondrial DNA. Mol Phylogenet Evol 2005, 37:153-164.

20. Hedin MC: Molecular phylogenetics at the population/species interface in cave spiders of the southern Appalachians (Araneae: Nesticidae: Nesticus). Mol Biol Evol 1997, 14:309-324.

21. Derkarabetian S, Steinmann DB, Hedin M: Repeated and time-correlated morphological convergence in cave-dwelling harvestmen (Opiliones, Laniatores) from montane western North America. PLOS ONE 2010, 5:e10388.

22. Snowman CV, Zigler KS, Hedin M: Caves as islands: mitochondria phylogeography of the cave-obligate spider species Nesticus barri (Araneae: Nesticidae). J Arachnol 2010, 38:49-57.

23. Caccone A: Gene flow in cave arthropods: a qualitative and quantitative approach. Evolution 1985, 39:1223-1235.

24. Verovnik R, Sket B, Trontelj P: Phylogeography of subterranean and surface populations of water lice Asellus aquaticus (Crustacea: Isopoda). Mol Ecol 2004, 13:1519-1532.

25. Niemiller ML, Fitzpatrick BM, Miller BT: Recent divergence with gene flow in Tennessee cave salamanders (Plethodontidae: Gyrinophilus) inferred from gene genealogies. Mol Ecol 2008, 17:2258-2275.

26. Martinsen L, Venanzetti F, Bachmann L: Phylogeography and mitochondrial DNA divergence in Dolichopoda cave crickets (Orthoptera, Rhahidophoridae). Hereditas 2009, 146:33-45.

27. Chiari Y, Van der Meijden A, Mucedda M, Lourenço JM, Hochkirch A, Veith M: Phylogeography of Sardinian cave salamanders (genus Hydromantes) is mainly determined by geomorphology. PLOS ONE 2012, 7:e32332.

28. Niemiller ML, McCandless JR, Reynolds RG, Caddle J, Tillquist CR, Near TJ, Pearson WD, FitzPatrick BM: Effects of climatic and geological processes during the Pleistocene on the evolutionary history of the northern cavefish, Amblyopsis spelaea (Teleostei: Amblyopsidae). Evolution 2013, 67:1011-1025.

29. Sissom WD, Reddell JR: Cave scorpions of Mexico and the United States [Escorpiones de cuevas de México y Estados Unidos]. Texas Mem Mus, Speleological Monogr 2009, 7:19-32.

30. Stockwell SA: The Scorpions of Texas (Arachnida, Scorpiones), M.S. Thesis. Texas Tech University; 1986.

31. Francke OF, Savary WE: A new troglobitic Pseudouroctonus Stahnke (Scorpiones: Vaejovidae) from northern Mexico. Zootaxa 2006, 1302:21-30

32. Bryson RW, Riddle BR, Graham MR, Smith BT, Prendini L: As old as the hills: montane scorpions in southwestern North America reveal ancient associations between biotic diversification and landscape history. PLOS ONE 2013, 8:e52822.

33. Bryson RW, Savary WE, Prendini L: Biogeography of scorpions in the Pseudouroctonus minimus complex (Vaejovidae) from south-western North America: implications of ecological specialization for pre-Quaternary diversification. J Biogeogr 2013, 40:1850-1860.

34. Stephens M, Donnelly P: A comparison of Bayesian methods for haplotype reconstruction from population genotype data. Am J Hum Genet 2003, 73:1162-1169.

35. Martin DP, Lemey P, Lott M, Moulton V, Posada D, Lefeuvre P: RDP3: a flexible and fast computer program for analyzing recombination. Bioinformatics 2010, 26:2462-2463.

36. Librado P, Rozas J: DnaSP v5: A software for comprehensive analysis of DNA polymorphism data. Bioinformatics 2009, 25:1451-1452.

37. Tajima F: Statistical method for testing the neutral mutation hypothesis by DNA polymorphism. Genetics 1989, 123:585-595.

38. Fu Y-X: Statistical neutrality of mutations against population growth, hitchhiking and background selection. Genetics 1997, 147:915-925.

39. Excoffier L, Lischer HEL: Arlequin suite ver 3.5: a new series of programs to perform population genetics analyses under Linux and Windows. Mol Ecol Resour 2010, 10:564-567.
40. Development Core Team R: R: A Language and Environment for Statistical Computing. Vienna, Austria: R Foundation for Statistical Computing; 2012

41. Drummond AJ, Suchard MA, Xie D, Rambaut A: Bayesian phylogenetics with BEAUti and the BEAST 1.7. Mol Biol Evol 2012, 29:1969-1973.

42. Posada D: jModelTest: phylogenetic model averaging. Mol Biol Evol 2008, 25:1253-1256.

43. Tamura K, Peterson D, Peterson N, Stecher G, Nei M, Kumar S: MEGA5: molecular evolutionary genetics analysis using maximum likelihood, evolutionary distance, and maximum parsimony methods. Mol Biol Evol 2011, 28:2731-2739.

44. Ferrari L: Miocene shearing along the northern boundary of the Jalisco block and the opening of the southern Gulf of California. Geology 1995, 23:751-754.

45. Oskin M, Stock J: Marine incursions synchronous with plate-boundary localization in the Gulf of California. Geology 2003, 31:23-26.

46. Ronquist F, Teslenko M, Van der Mark P, Ayres DL, Darling A, Höhna S, Larget B, Liu L, Suchard MA, Huelsenbeck JP: MrBayes 3.2: efficient Bayesian phylogenetic inference and model choice across a large model space. Syst Biol 2012, 61:539-542.

47. Rambaut A, Drummond AJ: Tracer v1.4. 2007. Available at http://beast.bio ed.ac.uk/Tracer.

48. Drummond AJ, Ho SYW, Rawlence N, Rambaut A: A rough guide to BEAST 1.4. 2007. Available at http://beast.bio.ed.ac.uk/Main_Page.

49. Gantenbein B, Largiadèr CR: The phylogeographic importance of the Strait of Gibraltar as a gene flow barrier in terrestrial arthropods: a case study with the scorpion Buthus occitanus as model organism. Mol Phylogenet Evol 2003, 28:119-130.

50. Gantenbein B, Fet V, Gantenbein-Ritter IA, Balloux F: Evidence for recombination in scorpion mitochondrial DNA (Scorpiones: Buthidae). Proc R Soc B 2005, 272:697-704

51. Graham MR, Jaeger JR, Prendini L, Riddle BR: Phylogeography of the Arizona hairy scorpion (Hadrurus arizonensis) supports a model of biotic assembly in the Mojave Desert and adds a new Pleistocene refugium. J Biogeogr 2013, 40:1298-1312.

52. Graham MR, Jaeger JR, Prendini L, Riddle BR: Phylogeography of Beck's Desert Scorpion, Paruroctonus becki, reveals Pliocene diversification in the Eastern California Shear Zone and postglacial expansion in the Great Basin Desert. Mol Phylogenet Evol 2013, 69:502-513.

53. Suzuki Y, Bohonak AJ: Isolation by resistance, web service. version 0.1 beta. 2010. Available at http://ibdws.sdsu.edu/ ibdws/ibrws.html.

54. Jensen JL, Bohonak AJ, Kelley ST: Isolation by distance, web service, v3.23. BMC Genetics 2005, 6:13.

55. Lemey P, Rambaut A, Welch JJ, Suchard MA: Phylogeography takes a relaxed random walk in continuous space and time. Mol Biol Evol 2010, 27:1877-1885.

56. Bielejec F, Rambaut A, Suchard MA, Lemey P: SPREAD: spatial phylogenetic reconstruction of evolutionary dynamics. Bioinformatics 2011, 27:2910-2912

57. Minin VN, Bloomquist EW, Suchard MA: Smooth skyride through a rough skyline: Bayesian coalescent-based inference of population dynamics. Mol Biol Evol 2008, 25:1459-1471.

58. Drummond AJ, Rambaut A, Shapiro B, Pybus OG: Bayesian coalescent inference of past population dynamics from molecular sequences. Mol Biol Evol 2005, 22:1185-1192.

59. Ho SYW, Shapiro B: Skyline-plot methods for estimating demographic history from nucleotide sequences. Mol Ecol Resour 2011, 11:423-434

60. Hijmans RJ, Cameron SE, Parra JL, Jones PG, Jarvis A: Very high resolution interpolated climate surfaces for global land areas. Int J Climatol 2005, 25:1965-1978

61. Braconnot $P$, Otto-Bliesner B, Harrison $S$, Joussaume $S$, Peterchmitt J-Y, Abe-Ouchi A, Crucifix M, Driesschaert E, Fichefet T, Hewitt CD, Kageyama M, Kitoh A, Laîné A, Loutre M-F, Marti O, Merkel U, Ramstein G, Valdes P, Weber SL, Yu Y, Zhao Y: Results of PMIP2 coupled simulations of the Mid-Holocene and Last Glacial Maximum - Part 1: experiments and large-scale features. Clim Past 2007, 3:261-277.

62. ESRI [Environmental Systems Research Institute]: ArcMap Version 10.0. Redlands, California: ESRl; 2010.

63. Araujo MB, New M: Ensemble forecasting of species distributions. Trends Ecol Evol 2007, 22:42-47.

64. Buisson L, Thuiller W, Casajus N, Lek S, Grenouillet G: Uncertainty in ensemble forecasting of species distribution. Glob Change Biol 2010, 16:1145-1157. 
65. McCullagh P, Nelder JA: Generalized Linear Models. 2nd edition. Boca Raton: Chapman \& Hall/CRC; 1999

66. Guisan A, Edwards TC, Hastie T: Generalized linear and generalized additive models in studies of species distributions: setting the scene. Ecol Model 2002, 157:89-100.

67. Elith J, Leathwick JR, Hastie T, Dudík M, Chee YE, Yates CJ: A working guide to boosted regression trees. J Anim Ecol 2008, 77:802-813.

68. Elith J, Phillips SJ, Hastie T: A statistical explanation of MaxEnt for ecologists. Divers Distrib 2011, 17:43-57.

69. Phillips SJ, Anderson RP, Schapire RE: Maximum entropy modeling of species geographic distributions. Ecol Model 2006, 190:231-259.

70. Hastie T: gam: Generalized Additive Models. R package version 1.06.2. 2011. Available at http://CRAN.R-project.org/package=gam.

71. Venables WN, Ripley BD: Modern Applied Statistics with S. New York: Springer; 2002

72. Hijmans RJ, Phillips S, Leathwick JR, Elith J: dismo: species distribution modeling. $R$ package version 0.7-17. 2012. Available at http://CRAN.Rproject.org/package=dismo

73. Ridgeway G: gbm: Generalized Boosted Regression Models. R package version 1.6-3.1. 2012. Available at http://CRAN.R-project.org/package=gbm.

74. Gertsch WJ, Soleglad ME: Studies of North American scorpions of the genera Uroctonus and Vejovis (Scorpionida, Vejovidae). Bull Am Mus Nat Hist 1972, 148:549-608.

75. McWest KJ: Tarsal spinules and setae of vaejovid scorpions (Scorpiones: Vaejovidae). Zootaxa 2001, 2009:1-126.

76. Van der Wal J, Shoo LP, Graham C, William SE: Selecting pseudo-absence data for presence-only distribution modeling: how far should you stray from what you know? Ecol Model 2009, 220:589-594.

77. Barbet-Massin M, Jiguet F, Albert CH, Thuiller W: Selecting pseudoabsences for species distribution models: how, where and how many? Methods Ecol Evol 2012, 3:327-338.

78. Hijmans RJ, Van Etten J: raster: geographic analysis and modeling with raster data. $\mathrm{R}$ package version 1.9-67. 2012. Available at http://CRAN:Rproject.org/package=raster.

79. Bivand RS, Pebesma EJ, Gomez-Rubio V: Applied Spatial Data Analysis with R. New York: Springer; 2008

80. Keitt TH, Bivand R, Pebesma E, Rowlingson B: rgdal: bindings for the Geospatial Data Abstraction Library. R package version 0.7-22. 2012. Available at http://CRAN.R-project.org/package=rgdal.

81. Ridgeway G: Generalized Boosted Models: a guide to the gbm package. 2006. Available at http://cran.r-project.org/web/packages/gbm/index.html.

82. Fielding $\mathrm{AH}$, Bell JF: A review of methods for the assessment of prediction errors in conservation presence/absence models. Environ Conserv 1997, 24:38-49

83. Allouche O, Tsoar A, Kadmon R: Assessing the accuracy of species distribution models: prevalence, kappa and the true skill statistic (TSS). J Appl Ecol 2006, 43:1223-1232.

84. Liu CR, Berry PM, Dawson TP, Pearson RG: Selecting thresholds of occurrence in the prediction of species distributions. Ecography 2005, 28:385-393.

85. Sauquet H, Ho SYW, Gandolfo MA, Jordan GJ, Wilf P, Cantrill DJ, Bayly MJ, Bromham L, Brown GK, Carpenter RJ, Lee DM, Murphy DJ, Sniderman JMK, Udovicic F: Testing the impact of calibration on molecular divergence times using a fossil-rich group: the case of Nothofagus (Fagales). Syst Biol 2012, 61:289-313.

86. Wilson JA: Miocene formations and vertebrate biostratigraphic units, Texas coastal plain. Am Assoc Petroleum Geologists Bull 1956, 40:2233-2246.

87. Ward B: Geologic history as it relates to modern vegetation patterns of South Central Texas. In Convergence and Diversity: Native Plants of South Central Texas. Native Plant Society of Texas Symposium Proceedings. Edited by Lautzenheiser E, Leslie-Pasztor P, Merritt J, Miller M, Millsaps L, Ward B. San Antonio, Texas: Native Plant Society of Texas; 2006:1-13.

88. White K, Davidson GR, Paquin P: Hydrologic evolution of the Edwards Aquifer recharge zone (Balcones fault zone) as recorded in the DNA of eyeless Cicurina cave spiders, south-central Texas. Geology 2009, 37:339-342.

89. Jackson ST, Overpeck JT: Responses of plant populations and communities to environmental changes of the Late Quaternary. Paleobiology 2000, 26:194-220.

90. Miller AL, Makowsky RA, Formanowicz DR, Prendini L, Cox CL: Cryptic genetic diversity and complex phylogeography of the boreal North American scorpion, Paruroctonus boreus (Vaejovidae). Mol Phylogenet Evol 2013. 10.1016/j.ympev.2013.11.005.
91. Yamashita T, Rhoads DD: Species delimitation and morphological divergence in the scorpion Centruroides vittatus (Say, 1821): insights from phylogeography. PLoS One 2013, 8:e68282.

92. Estep MC, Connell MU, Henson RN, Murrell ZE, Small RL: Testing a vicariance model to explain haplotype distribution in the psammophilic scorpion Paruroctonus utahensis. Southwest Nat 2005, 50:150-157.

93. Rull V: On microrefugia and cryptic refugia. J Biogeogr 2010, 37:1623-1627.

94. Hillis DM, Chamberlain DA, Wilcox TP, Chippendale PT: A new species of subterranean blind salamander (Plethodontidae: Hemidactyliini: Eurycea: Typhlomolge) from Austin, Texas, and systematic revision of central Texas paedomorphic salamanders. Herpetologica 2001, 57:266-280.

95. Wiens JJ, Chippindale PT, Hillis DM: When are phylogenetic analyses misled by convergence? A case study in Texas cave salamanders. Syst Biol 2003, 52:501-514.

96. Baird AB, Krejca JK, Reddell JR, Peden CE, Mahoney MJ, Hillis DM: Phylogeographic structure and color pattern variation among populations of Plethodon albagula on the Edwards Plateau of Central Texas. Copeia 2006, 4:760-768.

97. Lucas LK, Gompert Z, Ott JR, Nice CC: Geographic and genetic isolation in spring-associated Eurycea salamanders endemic to the Edwards Plateau region of Texas. Conserv Genet 2008, 10:1309-1319.

98. Taylor SJ, Weckstein JD, Takiya DM, Krejca JK, Murdoch JD, Veni G, Johnson KP, Reddell JR: Phylogeography of cave crickets (Ceuthophilus spp.) in central Texas: a keystone taxon for the conservation and management of federally listed endangered cave arthropods. III Nat Hist Surv Tech Rep 2007, 58:1-45.

99. Paquin P, Hedin M: The power and perils of 'molecular taxonomy': a case study of eyeless and endangered Cicurina (Araneae: Dictynidae) from Texas caves. Mol Ecol 2004, 13:3239-3255.

doi:10.1186/1471-2148-14-9

Cite this article as: Bryson et al:: Caves as microrefugia: Pleistocene phylogeography of the troglophilic North American scorpion Pseudouroctonus reddelli. BMC Evolutionary Biology 2014 14:9.

\section{Submit your next manuscript to BioMed Central and take full advantage of:}

- Convenient online submission

- Thorough peer review

- No space constraints or color figure charges

- Immediate publication on acceptance

- Inclusion in PubMed, CAS, Scopus and Google Scholar

- Research which is freely available for redistribution

Submit your manuscript at www.biomedcentral.com/submit
C Biomed Central 